\title{
Capturing the essence of a corporate brand personality: A Western brand in Eastern Europe
}

Received (in revised form): I3th January 2006

\section{JOHAN VAN REKOM}

is Assistant Professor in Marketing Research at the Department of Marketing at the Rotterdam School of Management, Erasmus University Rotterdam. His research interests include organizational identity, employee motivation, corporate communication and brand positioning.

\section{GABRIELE JACOBS}

is Assistant Professor in Organizational Behavior at the Department of Personnel and Organization at the Rotterdam School of Management, Erasmus University Rotterdam. Her research interests include brand management, crosscultural management and organisational justice.

\section{PEETER W. J.VERLEGH}

is Assistant Professor in marketing at RSM Erasmus University. He studies consumer behaviour and advertising, with an interest in social and cultural influences on consumer behaviour. Specific topics include country-of-origin effects, word-of-mouth, and social influence.

\section{KLEMENT PODNAR}

is Assistant Professor in Marketing communication at the Marketing Communication and Public Relations Department at the Faculty of Social Sciences, University of Ljubljana. His research interests include corporate and organizational identity, identification and reputation, corporate communication, marketing management and visual communications.

\section{Keywords \\ corporate brand; brand essence; \\ corporate communication; Eastern Europe; McDonald's}

\author{
Abstract \\ This study focuses on the positioning of a Western brand (McDonald's) in an Eastern European \\ market (Slovenia), and shows how corporate communication efforts can influence consumer \\ perceptions of brand essence. In order to ensure the long-time viability of a brand's equity, \\ preserving and reinforcing its essence is of primordial importance. A method is presented for \\ identifying those characteristics of the personality of a corporate brand that make up its \\ essence. Such a tool is suitable for refined corporate positioning, because it not only shows \\ which corporate characteristics form the essence of the corporate brand, but also shows why they \\ are so essential. \\ Journal of Brand Management (2006) 14,114-124. doi:10.1057/palgrave.bm.2550056
}

\section{INTRODUCTION}

Fifteen years after the fall of the iron curtain, many Western multinational companies are rapidly entering the East European market. ${ }^{1}$ Multinational companies such as McDonald's, Microsoft, $P \& G$, Beiersdorf, Unilever and Nokia have stable operations in East European coun- tries. Marketing managers have a strong interest in globally harmonising the image of their brands. At an increasing rate, they are standardising logos, brand names and advertising across countries, in order to communicate a consistent image across different countries. Even if brand communication is identical across countries, it is 
not self-evident that consumers in different countries hold similar images of the brand. The same product can have different functions across countries. For instance, fast food consumption is shown to be contingent on the cultural meaning of the social setting of eating. ${ }^{2}$ Moreover, a consumer's image of a brand is based on a multitude of information, often beyond the control of marketers. Marketing communication is just a part of the whole picture, and brand images are strongly influenced by reports in the popular (business) press, by consumers' experiences with a brand, and by word-of-mouth. ${ }^{3}$ Given these heterogeneous sources of information, it is important for companies to have a solid understanding of how consumers actually perceive the essence of their brand. This is an extra challenge to the key aim of corporate brand management, which is to secure loyalty from the different audiences with which a brand communicates. $^{4}$

The processing of marketing information depends on former market experiences of the customers. ${ }^{5}$ In particular, having a Western country of origin may be a brand feature of high salience for consumers in Eastern European markets. In general, 'Western' has been perceived as a favourable brand attribute. Batra et al. state ${ }^{6}$ : 'It is possible that the apparent increase in demand across the world for certain well-known brands such as Coca Cola and Levi's is largely because they are seen by consumers ... as symbols of the freedom and affluent lifestyles of the West'. In Eastern Europe, this also appeared to be the case shortly after the fall of communism. In 1993, Ger et al. state': 'Status goods are nearly inevitably foreign. This was true before the revolution, but then scarcity made such goods very hard to acquire. Now it is more a matter of their greater cost, plus their continued associa- tion with foreign lifestyles, that imparts status to their owners'. The favourability of the 'Western-iconness' might, however, have turned into a liability today. In 2005, Coulter et al. ${ }^{8}$ observe in Hungary: 'Consumers had access to a marketplace with new product and brand choices, and their reactions to this new cultural order included a mixture of desire, ambivalence, skepticism, and confusion'. Given these developments, and given the aforementioned heterogeneity of signals consumers receive about a brand, it is highly desirable for marketers to know the consumer perception of brand essence. Of specific interest is to investigate which meaning the corporate brand attribute 'Western' has nowadays in the changing environment of the East European market.

To address these issues, we present a theoretical framework that provides insight into the essence of brands. We first introduce the concept of brand essence within the broader context of brand identity, and elaborate upon the concept of essence from a consumer perspective. In our empirical section, we apply these concepts to the positioning of a quintessentially Western brand (McDonald's) in an East European country (Slovenia). We investigate Slovenian consumer perceptions of the essence of the McDonald's brand, and illustrate how these perceptions can guide brand communications.

\section{BRAND ESSENCE AS A TOOL FOR MANAGEMENT}

Scholars have developed a rich set of conceptual tools that help managers to define a positioning strategy for their brand. One of the basic building blocks for brand strategists is brand identity, which is the set of brand associations that 
the brand strategist aims to create or maintain. ${ }^{9}$ Typically, brand identity consists of 6-12 dimensions, which are likely to remain constant over time and context. ${ }^{10,11}$ Within this set of dimensions, the most important element is the brand essence. This essence is often captured by a brief phrase, 'a single thought that captures the soul of the brand, ${ }^{, 12}$ and this is linked to all of the core elements of the brand's identity, like a hub is linked to the spokes of a wheel. ${ }^{13,14}$ In the long run, the value of a brand can only be maintained if such adjustments reinforce the essence of a brand for consumers. ${ }^{15,16}$

Consumers are full-blown partners in the co-creation of brand essence and import of meanings from beyond the marketplace. ${ }^{17}$ But how do we establish what consumers perceive to be the essence of a brand? The current marketing literature has little to offer for brand managers, who are constantly faced with the challenge of renewing their brand without loosing its essence and alienating its customers; and there is a need for comprehensive and dynamic models that reflect the relationship between brand information that consumers receive and their current brand representations of the brand. $^{18}$

In the next section, we develop a consumer-based approach to corporate brand essence. We approach this issue from the point of view of the brand's personality: personality traits are often used to design and communicate a brand positioning and are readily translatable into appealing communication. ${ }^{19}$ In order to illustrate our approach to the essence of corporate brands, we will investigate how customers in Slovenia view the personality of McDonald's. Our results will be translated into recommendations for brand management. In addition, we will intro- duce a number of suggestions for further research.

\section{CORPORATE BRAND ESSENCE: THE ROLE OF PERCEIVED CAUSALITY}

Although a general agreement exists that brands can be conceptualised as sets of characteristics, views on how those characteristics hang together are not that well articulated. Brand personality can be seen as the set of human characteristics associated with a brand ${ }^{20}$ which is connected in consumer memory to numerous other brand features. ${ }^{21}$ To organise these associations, consumers have 'naïve theories' that (causally) link the different characteristics of the brand. ${ }^{22}$ For instance, a study of German local energy providers showed that customers attached great importance to the 'local' character of the company, because they felt that a 'local' company was better able to understand and meet the expectations of customers. 'Local' was perceived to be causally linked to 'customer orientation'. ${ }^{23}$

Such 'naïve theories' can help us trace the essence of brands. The principle is straightforward: consumers perceive brand characteristics (like 'local' and 'customer oriented') to be related to each other, and these causal relations form a network of associations around the brand. In this network, some characteristics matter more than others, because they are perceived to 'cause' a larger number of the other characteristics. Similar to the view of brand essence as the hub that connects the spokes of brand associations, the characteristic (or characteristics) that consumers perceive to cause the largest number of other characteristics can be regarded as brand essence from a consumer perspective. ${ }^{24,25}$ Operationalised in this manner, brand essence becomes a property that resides within the customers 
of a brand, and can be measured and tracked.

To further develop this conceptualisation of brand essence, we rely on Ahn's theory of essence, ${ }^{26}$ which is rooted within cognitive psychology. In line with Murphy and Medin, ${ }^{27}$ Ahn argued that people's ideas about reality often take the form of 'naïve theories', in which various characteristics of an object are causally related. Ahn found that people generally attach greater importance to the characteristics that they perceive to underlie one or more other characteristics. A characteristic that is perceived to cause a greater number of characteristics is perceived to be more 'essential' to a concept. Van Rekom et al. ${ }^{28}$ applied Ahn's ${ }^{29}$ proposition in a marketing setting, and found that the more consumers believed a characteristic to cause the other characteristics of the brand, the more they perceived that characteristic to form the essence of that brand. In this way, brand essence can be measured by establishing the causal relationships between all features. Thus, the entire causal structure of a brand's identity is mapped. This 'map' shows managers why certain characteristics are seen as essential. The causal approach may prevent marketers from making serious mistakes when they (re)position their brands. For instance, Camel successfully built up a market share featuring a rugged man, who travelled miles across the jungle in order to get his cigarette. In 1990, the brand completely changed its character, moving from the 'rugged' and 'outdoorsy' character to a funny looking plush camel that was perhaps 'relaxed' and 'funny', but in no way rugged and tough. This betrayal to the brand's identity had disastrous consequences: within four years, Camel's market share had eroded by more than 50 per cent. ${ }^{30}$

\section{INVESTIGATING THE ESSENCE OF A CORPORATE BRAND: THE CASE OF MCDONALD'S SLOVENIA}

For managers in charge of corporate communication, the key question, now, becomes: how likely are consumers to incorporate information that has been communicated by the organisation into how they see the brand. In particular, one may ask, to what extent do the features that an organisation communicates about itself penetrate into its essence. If this happens, consumers will start to see communicated features as core features of the brand, and this implies that, even though consumers may build their own theories about the brand, there is still a fair degree of malleability of the brand for the marketer.

The setting for this research was Slovenia. McDonald's Slovenia was founded in 1993 as a subsidiary of McDonald's Corporation (USA). Today McDonald's Slovenia, which strictly follows the global corporate philosophy, has 16 restaurants, with more then 650 employees, who serve, according to their own figures, 20,000 people a day (Table 1).

In Autumn 2005, McDonald's Slovenia started a new marketing communication campaign with an advertisement that was extremely fast-paced. The main communication tools were television, press, internet and SMS. The target groups of this campaign were youngsters, students and scholars, aged 14-25 years. When the campaign, which is a part of a broader McDonald's campaign under the slogan 'i'm lovin' it', was out for about two months, the research project took off. We will first describe the qualitative phase, in which we establish the brand characteristics that might be relevant. We next describe a survey in which we investigated the essence of McDonald's in Slovenia and the role communication 
Table I Development of McDonald's Slovenia

\begin{tabular}{lcccc}
\hline Year & $\begin{array}{l}\text { Number of } \\
\text { restaurants }\end{array}$ & $\begin{array}{l}\text { Number of } \\
\text { guests per year }\end{array}$ & $\begin{array}{l}\text { Number of } \\
\text { employees }\end{array}$ & $\begin{array}{l}\text { Income in SIT } \\
\text { (240 SIT=I } \\
\text { EURO) }\end{array}$ \\
\hline 1993 & 1 & 100,000 & 75 & $30,000,000$ \\
1994 & 3 & 850,000 & 120 & $300,000,000$ \\
1995 & 5 & $1,900,000$ & 190 & $750,000,000$ \\
1996 & 8 & $2,600,000$ & 310 & $1,300,000,000$ \\
1997 & 9 & $3,800,000$ & 360 & $2,100,000,000$ \\
1998 & 11 & $4,000,000$ & 450 & $2,300,000,000$ \\
1999 & 14 & $4,100,000$ & 540 & $2,500,000,000$ \\
2000 & 15 & $4,400,000$ & 570 & $2,800,000,000$ \\
2001 & 16 & $4,500,000$ & 600 & $3,050,000,000$ \\
2002 & 17 & $4,600,000$ & 650 & $3,300,000,000$ \\
2003 & 17 & $4,700,000$ & 650 & $3,500,000,000$ \\
2004 & 17 & $6,500,000$ & 650 & $3,500,000,000$ \\
2005 & 16 & $6,300,000$ & 600 & $3,520,000,000$ \\
\hline
\end{tabular}

Source: We thank Mc Donald's Slovenia for this information.

may have had in the formation of this essence.

The features for the questionnaire were gathered in street intercept interviews in the centre of Ljubljana. Thirty persons, aged between 15 and 25 years, were asked what person McDonald's would be, if it was a human being. They provided up to five key words per person. Additionally, they were asked to provide up to five key words for human characteristics they associated with McDonald's recent communication. We checked whether they had ever worked for McDonald's and excluded former employees. Eleven characteristics were mentioned by four or more respondents: fast, happy, interesting, pushy, kind, lively, young, communicative, open, relaxed and sociable (Table 2). These words were taken as the input characteristics for the questionnaire. Two characteristics were added: the feature 'successful' was added, as McDonald's strongly emphasises this feature in its own communication, ${ }^{31}$ as well as 'Western'. This last characteristic was deemed to be relevant, as Slovenia is one of the countries in Eastern Europe that has lived a long time under a communist regime and we were especially interested in the question of which role the Western-ness of the corporate brand plays in the minds of Slovenian consumers.

The essence of each characteristic was derived as follows. The questionnaire included 13 tables (one for each characteristic) on which consumers could rate their perception of the relations between that characteristic and the 12 others. The order of the characteristics was randomised. Each table contained a list of 12 statements like this: McDonald's is [characteristic A], because McDonald's is [characteristic B]. For example, the table for the characteristic 'sociable' included 12 statements like 'McDonald's is sociable because McDonald's is communicative'. For each combination, respondents could check one of the following answers: 'no, on the contrary', 'these two characteristics are unrelated', 'I agree, but this does not apply to Mc Donald's', 'Yes, I agree'. These answers were used as input for a measure of perceived causation of each characteristic. The responses were coded according 
Table 2 Averages and standard deviations for characteristics of McDonald's

\begin{tabular}{|c|c|c|c|c|c|c|}
\hline & \multicolumn{2}{|c|}{ Qualitative results* } & \multicolumn{2}{|c|}{ Quantitative results**,*** } & \multirow[b]{2}{*}{$\begin{array}{l}\text { Perceived } \\
\text { necessity }\end{array}$} & \multirow[b]{2}{*}{ Causality } \\
\hline & McDonald's & Campaign & Liking & Communication & & \\
\hline Fast & 8 & 2 & $3.54(1.07)$ & $3.71(1.34)$ & $5.17(1.95)$ & 4.49 (4.09) \\
\hline Happy & 6 & 7 & $3.39(1.11)$ & $4.02(1.08)$ & $4.52(I .8 I)$ & $5.67(4.26)$ \\
\hline Interesting & 0 & 5 & $3.10(1.20)$ & $3.48(1.17)$ & 4.37 (1.91) & $3.82(4.43)$ \\
\hline Pushy & 5 & 4 & $2.66(1.32)$ & $3.00(1.57)$ & $4.37(1.85)$ & $1.53(5.74)$ \\
\hline Kind & 14 & 10 & $2.93(1.21)$ & $3.10(1.36)$ & $4.20(1.87)$ & $2.17(4.72)$ \\
\hline Lively & 5 & 5 & $3.23(1.23)$ & $3.79(1.20)$ & $4.75(1.88)$ & $5.16(4.42)$ \\
\hline Youthful & 3 & 7 & $3.15(1.03)$ & $3.88(1.14)$ & 4.53 (I.79) & $4.92(4.68)$ \\
\hline Communicative & 4 & 3 & $3.49(1.12)$ & $3.66(1.21)$ & 4.61 (1.97) & $5.75(4.49)$ \\
\hline Open & 3 & 4 & $3.36(1.08)$ & $3.86(1.08)$ & $4.46(1.73)$ & $5.8 I(4.50)$ \\
\hline Relaxed & I & 4 & $3.27(1.13)$ & $3.97(1.07)$ & $4.21(1.74)$ & $5.25(4.57)$ \\
\hline Sociable & 3 & 4 & $3.33(1.09)$ & 3.99 (1.07) & $4.28(1.69)$ & $5.78(4.54)$ \\
\hline Western & 0 & 0 & 2.77 (1.27) & $3.40(1.34)$ & $4.70(1.96)$ & $3.53(4.46)$ \\
\hline Successful & I & 0 & $3.30(1.10)$ & $3.74(1.20)$ & $4.60(1.79)$ & $4.32(4.58)$ \\
\hline
\end{tabular}

*The numbers represent the numbers of respondents mentioning the respective feature.

**The highest ratings have been rendered in bold typeface.

****The numbers between brackets represent standard deviations.

to the scheme developed by Van Rekom et al. ${ }^{32}$ : 'yes, I agree' was coded as 1 , while 'No, on the contrary' was coded as ' -1 ', because in this case one characteristic would impede the realisation of the other characteristic. The two other options ('these two are unrelated to each other', and 'I agree, but this does not apply to Mc Donald's') were coded '0'. Although these two options are not identical, they both reflect instances where a feature neither causes nor inhibits the other feature. It is noteworthy that the first option ('these two are unrelated to each other') comprises nearly 80 per cent of the zero scores in this coding scheme. The 'causal status' of each characteristic was computed for each respondent, by summing all 12 answers $(-1,0$ or 1$)$ for a single characteristic.

In addition to this construct, we took a direct measure of the perceived necessity of each feature for Mc Donald's. 'Perceived necessity' is related to the degree to which a characteristic causes the other charac- teristics of a brand. ${ }^{33}$ When one brand characteristic causes many other characteristics, the elimination of this feature implies that the consumer's whole image of the brand is likely to change. Since such a feature is highly essential, consumers will have the impression that the brand is no longer the same brand. ${ }^{34,35}$ To measure perceived necessity we asked respondents: 'Would Mc Donald's still be Mc Donald's without [characteristic A]?' (' 1 '= absolutely still McDonald's, '7'= absolutely no longer McDonald's). ${ }^{36}$ Additionally, we assessed to what extent respondents liked the different features, by asking: 'Please indicate how much you like [characteristic A] of McDonald's ('1'= I don't like it at all, '7'= I like it very much).

We also wanted to know to what extent consumers perceived that the marketing communication influenced their perception of the brand, therefore we asked them to what degree they thought McDonald's emphasised each of the 13 features in its communication. ('1'='McDonald's does 
not emphasise this feature at all', '7'='McDonald's emphasises this feature very much'). Respondents were asked whether they had working experience at McDonald's and in what media they had been confronted with communication from McDonald's, in order to make sure that everybody had been confronted with communication from McDonald's and that nobody had worked as an employee for McDonald's. As all respondents had seen communication from McDonald's, and none had worked for it, no respondents were excluded on this ground.

\section{RESULTS}

Students at several courses at the University of Ljubljana were invited to participate in the research project. They filled out the online questionnaires on a voluntary base. The website was contacted 550 times. Two hundred and forty-seven respondents filled in the questionnaire, which implies a response rate of 45 per cent. A student sample was thought warranted, as they belong to the age group targeted by McDonald's. Except for eight respondents, all had seen the television campaign, and these eight exceptions knew McDonald's from other media-so everybody had been confronted with communication from McDonald's. Table 2 lists the means and the standard deviations from the measures described above.

Table 2 shows that 'open' is the most essential feature of McDonald's in Slovenia, causing on average 5.81 other features per respondent. It is closely followed by 'sociable' (5.78), 'communicative' (5.75) and 'happy' (5.67). For every person, we calculated the correlations between the degree to which that person perceived McDonald's to emphasise that feature, the perceived necessity of the features, and the degree to which they believed each feature to cause the other features. Before averaging, correlations were subjected to a Fisher- $r$-to- $Z$ transformation. The average of these transformed values was then transformed back into a group-level correlation coefficient. ${ }^{37}$ Overall, perceived necessity shows a significant correlation with the causality of the characteristics: $r=0.23(p<0.001)$. More causal features were liked more $(r=0.37, \quad p<0.001)$ and respondents perceived a strong link between the marketing communication of McDonald's and the causal status of the features $(r=0.46, p<0.001)$.

For managers, the most interesting hands-on information is the pattern of causal relations among the characteristics. Table 3 shows the average agreements with all the relations among the characteristics. The only characteristic that conflicts with the others appears to be 'pushy', which conflicts most with 'kind' (rating of -0.23 ). Table 3 offers detailed information about the degree to which each characteristic depends upon any other, but the most insightful information can be distilled by drawing the overall cause map of respondents. We choose a cut-off level in such a way that the overall pattern becomes clear, while preventing the map from becoming too full and cluttered. In Table 3 , six relationships had agreement ratings of 60 per cent or higher and 34 relationships had agreement ratings between 50 per cent and 60 per cent. Figure 1 represents a map of causal relationships.

Figure 1 shows that 'open' sits like a spider in its web of meanings: because of its high causal status, it is at a central position in the figure, and is connected to many other concepts. 'Open' also seems to be a very good starting point for a communication strategy: it implies directly that McDonald's is 'communicative' and 


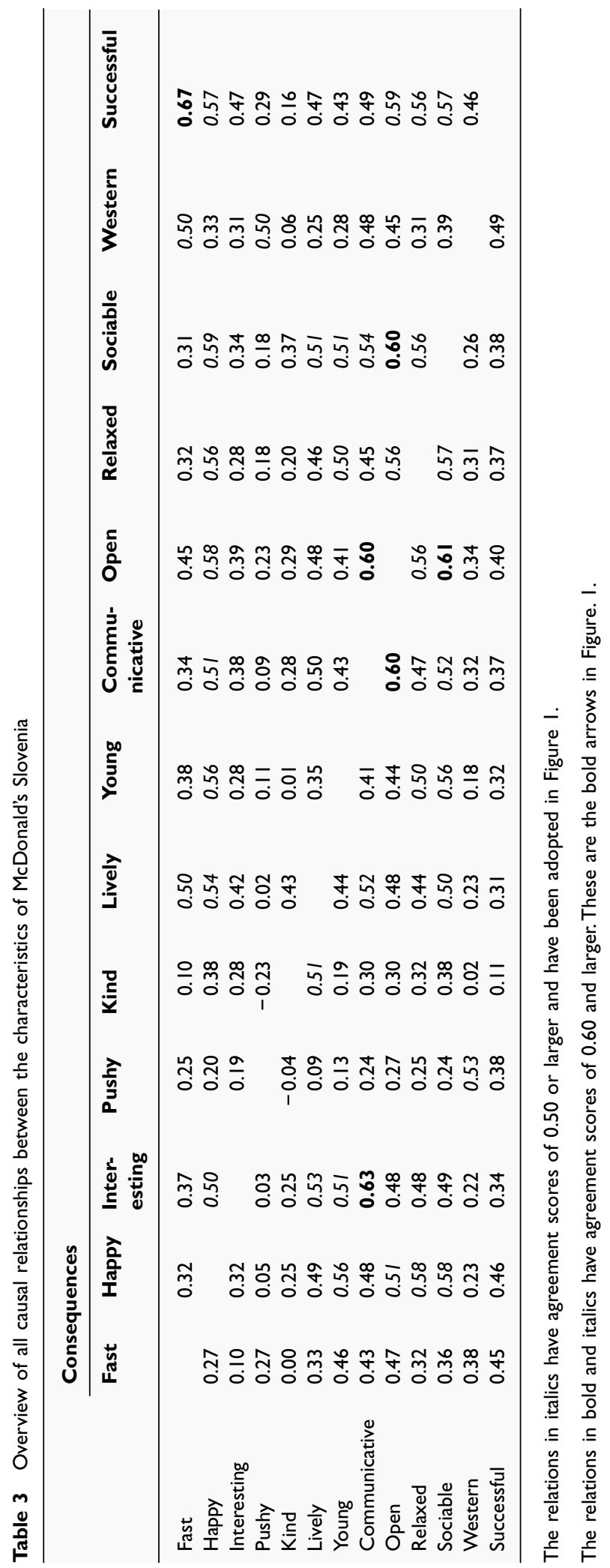




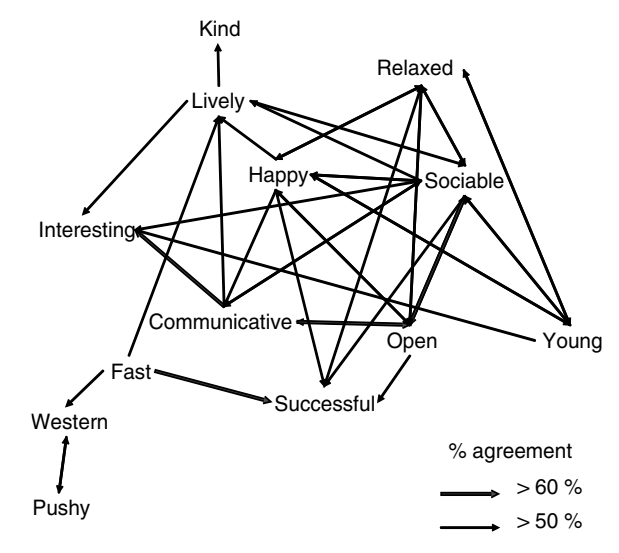

Figure I Deriving brand essence: the dominant causal relations among characteristics of McDonald's Slovenia

'sociable', which form a solid cluster of characteristics. 'Western' has a very low causal status (causing on average 3.53 out of 12 elements), which would on the first sight render it unimportant. The low score on liking (2.77 on a 7 -point-scale) indicates that 'Western' is not perceived as a positive aspect of the brand and the map indeed suggests that this characteristic should be handled with care, since it is the feature that causes and is caused by the only clearly negative attribute of the brand, namely 'pushy'. Figure 1 also makes visible that the feature 'fast' has a delicate position, since it causes 'Western' which is directly associated with 'pushy'. As this illustration shows, apart from uncovering the most essential characteristics of a brand, the results of our method also offer valuable guidelines on how to further shape the corporate brand.

The map in Figure 1 also illustrates an interesting aspect of this method: recall that the concepts 'Western' and 'successful' were added by the research team, in order to investigate the role of these concepts in Slovenian consumer perceptions of Mc Donald's. Although this concept has received quite some attention from marketing and consumer researchers, consumers never explicitly mentioned
'Western' or 'successful' as key features of the McDonald's brand. ${ }^{38}$ The map in Figure 1 confirms that consumers indeed do NOT see these concepts as essential: Using the 50 per cent cut-off level, 'Western' is perceived to be causally related to only one aspect of the McDonald's brand, and 'successful' is not perceived to cause any other feature. In terms of perceived causality, 'Western' ranks tenth, and 'successful' ranks eighth out of 12 features. In addition, when we exclude these two concepts from the analyses, the ranking of the causality of the other brand features does not change substantially, and the concepts of 'open', 'happy', 'young', 'communicative' and 'sociable' remain the most essential. This finding speaks to the robustness of our method, and illustrates that the management or researchers may incorporate (a small number of) extra features into the procedure without distorting the overall picture of brand associations. This aspect of our method is particularly useful for managers who want to investigate whether (and how) proposed changes in communication or positioning would relate to the perceived essence of the brand.

\section{DISCUSSION}

In this paper, we applied a method developed to describe product brand essence to the perception of a Western corporate brand in an East European market. The method differs from previous approaches in that it traces the causal relations among the brand characteristics, making visible how features cohere in consumer minds. Thus, it can be seen as a further development of approaches ${ }^{39}$ that measure brand essence by asking respondents whether or not a brand could do without a given feature, since the present method provides a richer view on what is essential. Our 
method uncovers consumer 'naïve theories' about why a certain feature makes up the essence of a brand. We found a significant correlation between the perceived necessity of the feature of a brand and its causality, which is in line with earlier findings. ${ }^{40} \mathrm{~A}$ positive finding for marketers in the field of corporate brands is that our respondents saw quite a strong link between the communication emphasis of McDonald's and their own perception of the essence and the liking of specific features. It seems that marketing communication is still a strong voice in the noisy choir of corporate brand-related signals.

Approaching essence via the causality of the features produces a more finegrained differentiation between the various characteristics that make up brand identity. As illustrated by Table 3 and Figure 1, the present approach provides detailed information about how and why consumers perceive coherence between certain characteristics. In doing so, our method not only shows which characteristics are most essential, but also why they are so central to the corporate brand. The resulting cognitive maps give managers hands-on information on how to optimise their brand positioning.

Our study also shows that Western corporate brands should be quite careful in communicating their Western origin in East European countries. Figure 1 shows that to many Slovenians, the mere fact that a company is 'Western' implies that it is pushy. A further advantage of the method presented here is the fact that the complete pattern of coherence is established per respondent. This implies that if marketers have reasons to assume the existence of different segments in the market, causal maps can be drawn for every separate segment, allowing a precise targeting of each of the market segments. This is of specific importance for global corporate brands that want to fine-tune their communication strategies for different national markets.

\section{CONCLUSION}

We present a method for charting the essence of corporate brands, which helps managers choose fine-grained positioning strategies that help ensure the long-term value of their corporate brand. The key success factor is that our method can pinpoint what the essence of a brand is in consumer eyes, and the causal pattern of relations between the characteristics of the brand helps managers to find effective ways to reinforce this essence. In the long run, brands that remain true to their essence have a better chance to maintain a favourable position in the consumer's mind. Brand managers can therefore benefit from a keen understanding of the essence of their brands, in order to develop marketing strategies that emphasise rather than conflict with this essence. ${ }^{41}$ Our method not only shows which features are most essential, but also why these are most essential. We also found that what consumers believe to be essential about the brand bears a relation with what the brand communicates, and would place further research into this area high on our agenda. Knowledge about consumer theories on why a brand is as it is, with information about which characteristic depends upon which other characteristic, can be used to create appealing and persuasive marketing communications that capitalise on these causal links.

\section{References and Notes}

(1) Al-Khatib, J.A., Robertson, C. J. and Lascu, D. -N. (2004) 'Post-communist consumer ethics: The case of Romania', Journal of Business Ethics, Vol. 54, pp. 81-95.

(2) Bagozzi, R. P., Wong, N., Abe, S. and Bergami, M. (2000) 'Cultural and situational contingencies 
and the theory of reasoned action: Application to fast food restaurant consumption', Journal of Consumer Psychology, Vol. 9, No. 2, pp. 97-106.

(3) Schultz, M. and De Chernatony, L. (2002) 'Introduction: The challenges of corporate branding', Corporate Reputation Review, Vol. 5, No. 2/3, pp. 105-112.

(4) Melewar, T. C, Hussey, G. and Srivoravilai, N. (2005) 'Corporate visual identity: The rebranding of France Telecom', Journal of Brand Management, Vol. 12, pp. 379-394 (p. 391).

(5) Berry, L. L., Carbone, L. P. and Haeckel, S. H. (2002) 'Managing the total customer experience', MIT Sloan Management Review, Vol. 43, No. 3, pp. 85-89.

(6) Batra, R., Myers, J. G. and Aaker, D. A. (1996) 'Advertising Management', 5th edn, Prentice Hall, Upper Saddle River, NJ, p. 716.

(7) Ger, G., Belk, R. W. and Lascu, D. N. (1993) 'The development of consumer desire in marketizing and developing economies:The cases of Romania and Turkey', Advances in Consumer Research, Vol. 20, pp. 102-107 (p. 104).

(8) Coulter, R. A., Price, L. L., Feick, L. and Micu, C. (2005) 'The evolution of consumer knowledge and sources of information: Hungary in transition', Journal of the Academy of Marketing Science, Vol. 33, pp. 604-619 (p. 605).

(9) Aaker, D. A. and Joachimsthaler, E. (2000) 'Brand Leadership', The Free Press, New York, p. 43.

(10) Aaker, D. A. (1996) 'Building Strong Brands', The Free Press, New York.

(11) De Chernatony, L. (2001) 'From Brand Vision to Brand Evaluation. Strategically Building and Sustaining Brands', Butterworth Heinemann, Oxford.

(12) Van Auken, B. (2000) 'Developing the brand building organization', Journal of Brand Management, Vol. 7, No. 4, pp. 281-290.

(13) Aaker and Joachimsthaler, ref. 9 above.

(14) Aaker and Joachimsthaler, ref. 9 above.

(15) Keller, K. L. (2003) 'Strategic Brand Management: Building, Measuring and Managing Brand Equity', 2nd edn, Prentice Hall, Upper Saddle River, NJ, p. 638.

(16) Kelly, T. (1998) 'Brand essence-making our brands last longer', Journal of Brand Management, Vol. 5, pp. 390-391 (p. 390).

(17) Brown, S., Kozinets, R.V. and Sherry, J. F. (2003) 'Teaching old brands new tricks: Retro branding and the revival of brand meaning', Journal of Marketing, Vol. 67, pp. 19-33.

(18) Johar, G. V., Sengupta, J. and Aaker, J. L. (2005) 'Two roads to updating brand personality impres- sions: Trait versus evaluative inferencing', Journal of Marketing Research, Vol. 42, pp. 458-469 (p. 469).

(19) De Chernatony, ref. 14 above.

(20) Aaker, J. L. (1997) 'Dimensions of brand personality', Journal of Marketing Research, Vol. 34, pp. 347-356.

(21) Freling, T. H. and Forbes, L. P. (2005) 'An examination of brand personality through methodological triangulation', Journal of Brand Management, Vol. 13, pp. 148-162 (p. 153).

(22) Murphy, G. L. and Medin, D. L. (1985) 'The role of theories in conceptual coherence', Psychological Review, Vol. 92, pp. 289-316.

(23) Wiedmann, K. -P. (2005) 'Measuring brand equity for organising brand management in the energy sector-a research proposal and first empirical hints', Journal of Brand Management, Vol. 12, pp. 207-209.

(24) Van Rekom, J., Jacobs, G. and Verlegh, P. (2006) 'Measuring and managing the essence of a brand personality', Marketing Letters, Vol. 17, pp. 181-192.

(25) Aaker and Joachimsthaler, ref. 9 above.

(26) Ahn, W. -K. (1998) 'Why are different features central for natural kinds and artifacts? The role of causal status in determining feature centrality', Cognition, Vol. 69, pp. 135-178.

(27) Murphy and Medin, ref. 22 above.

(28) Van Rekom, Jacobs and Verlegh, ref. 24 above.

(29) Ahn, ref. 26 above.

(30) Esch, F. -R. (2005) 'Strategie und Technik der Markenführung', 3rd edn, Vahlen, München, p. 18.

(31) Palmer, T. B. and Short, J. C. (2001) 'Why do Goliaths fail? Performance referents in successful organizations, Corporate Reputation Review, Vol. 4, pp. 209-222.

(32) Van Rekom, Jacobs and Verlegh, ref. 24 above.

(33) Van Rekom, Jacobs and Verlegh, ref. 24 above.

(34) Ahn, ref. 26 above.

(35) Michel, G. and Ambler, T. (1999) 'Establishing brand essence across borders', Journal of Brand Management, Vol. 6, pp. 333-345.

(36) Van Rekom, Jacobs and Verlegh, ref. 24 above.

(37) Rosenthal, R. (1991) 'Meta-analytic Procedures for Social Research', Applied Social Research Methods Series, Vol. 6. Sage, Beverly Hills.

(38), We thank our reviewers, whose critical remarks lead us to elaborate on this important issue.

(39) Michel and Ambler, ref. 34 above.

(40) Van Rekom, Jacobs and Verlegh, ref. 24 above.

(41) Keller, ref. 15 above. 